\title{
FORMATION OF TECHNOLOGICAL INDICES OF DRY POWDER OF CABBAGE
}

\author{
Alexandra Niemirich \\ Department of Molecular and avant-garde gastronomy \\ National University of Food Technologies \\ 68 Volodymyrska str., Kyiv, Ukraine, 01601 \\ nemirichav@gmail.com \\ Oksana Vasheka \\ Department of Foodstuff Expertise \\ National University of Food Technologies \\ 68 Volodymyrska str., Kyiv, Ukraine, 01601 \\ oksana.vasheka@ukr.net \\ Oksana Petrusha \\ Department of Foodstuff Expertise \\ National University of Food Technologies \\ 68 Volodymyrska str., Kyiv, Ukraine, 01601 \\ petrushaoo@ukr.net
}

Nikolay Pogozhikh

Department of Physical-mathematical and engineering-technical disciplines

Kharkiv State University of Food Technology and Trade

333 Klochkivska str., Kharkiv, Ukraine, 61051

avnemirich@mail.ru

\begin{abstract}
One of the resource-saving methods of drying, from the point of view of preserving food and biological value, providing the appropriate recovery properties of dried food products (DFP) and energy intensity of the process, is drying with mixed heat supply (MHS drying).

The scientific concept of work on the formation of a universal and DFP stable functional and technological potential is formulated, which is the basis for modeling and designing the formulation composition and technology of food products by groups and types with its use or interchangeability.

As the subject of research for the formation of quality indicators of cereals, white cabbage is selected, as it is a typical vegetable for Ukraine and accordingly has a high degree of assimilation of natural micronutrients in the human body.

Structural studies have shown the predominantly crystalline structure of polysaccharides, that is, less than their transformation under conditions of MHS drying, as compared with convective conditions.

The effect of MHS drying on the formation of DFP quality indicators is determined by the method of recording IR spectra with Fourier transform. For studies of the violation of total internal reflection, it has been established that the process of DFP reduction leads to an increase in the availability of organic substances in the solvent, which will facilitate the extraction of extractives in the recovery of raw materials.

It is established by the number of aroma, the more aromatic-forming substances are contained in the MHS drying samples irrespective of the process temperature, less in the dried samples of the convective method. This is due to the reduction of thermal and thermal effects during MHS drying, which slows down chemical transformations and removes aromatic substances.

It is proved by the tensometric method, with the convective method due to shrinkage during dehydration, the changes during sorption and desorption are insignificant. When MHS drying, such changes are expressed: during the sorption of vapors, DFP is well restored, the capillaries swell, so the differential distribution function of the pores expands, the average radius of the capillaries increases $4 . . .6$ times.

The research results make it possible to form the functional and technological parameters of cabbage powder, to simulate the formulation of new food products with this ingredient and to optimize the production technology.
\end{abstract}

Keywords: dried food products, drying with mixed heat and water, quality indicators, regression models, innovative forecast. 


\section{Introduction}

The main problematic positions of the efficiency of the functioning of the processing, food and restaurant industry institutions in the modern market conditions of Ukraine are: rational use of food raw materials and secondary products, efficient use of energy, human and financial resources, targeting consumers' needs, and creating state food stocks and for the diet of a special consumer contingent (geologists, military, climbers, fishermen, athletes).

Simultaneous analysis and solution of these problems allows to form the directions of attraction to technological flows of dried food products (DFP), which, from a physiological point of view, is a concentrate of all nutrients necessary for the human body, and with technological, semi-finished products of high degree of readiness.

In Ukraine there are several enterprises for the production of dried products. However, the volumes of their production and the range of products are slightly involved in the technological flows of the food industry and restaurants. In addition, the proposed methods of drying are energy-intensive and long-lasting, the technological properties of the final product do not always allow it to be widely used in food technology, and their functional and technological potential has not been sufficiently studied.

In this regard, the scientific concept of the work has been defined: the qualitative indicators of DFP - hydration, fat-loss, emulsifying ability, and the number of aroma-formed during drying, are determined by physicochemical and colloidal properties. It is the basis for improving and developing innovative technologies, expanding the assortment of food products allows adapt technologies for various production conditions (food industry enterprises, restaurant facilities, including bistro, as well as household and

The formation of the listed DFP qualitative indicators is determined to a certain extent, primarily by the way of dehydration of food raw materials. As the most innovative component of these methods, it is necessary to choose thermal drying as the most common in the food industry.

Now, the most promising methods of drying are methods of sublimation with cryodestruction, cold sawing and with mixed heat and moisture drying (MHS drying). These methods make it possible to obtain products with attractive organoleptic characteristics while maintaining high functional and technological properties. However, the first two methods of drying require the use of special equipment and significant energy costs. Of all the currently known methods, MHS drying [1-3] is considered to be energetically effective.

In addition to energy efficiency, this method is a definite approximation to freeze-drying, and, from the point of view of thermal effects on food raw materials, it is the most patchy. Therefore, based on the formulated concept during the research, only powders obtained by two methods of thermal drying were compared: MHS and the convective one.

The aim of research is studying the dependence of the formation of DFP quality indicators on the method and regimes of MHS drying, which will allow to optimize the formulation of products using these plant powders. In accordance with the purpose, the objectives of the study are:

- to study the influence of MHS drying regimes on the transformation of biopolymers and aromatizing substances of DFP (on the example of cabbage)

- to carry out a study of the existing capillary-porous structure of cereals from cabbage.

\section{Materials and Methods}

As the subject of research for the formation of quality indicators of cereals, cabbage is chosen as an example. This culture is characterized by high yield and at the same time has a low storage capacity. The production of powders from cabbage allows not only to preserve it as a component of the diet, but also contributes to the formation of an assortment of traditional products, their functional and technological properties. According to the results of their previous studies, it is established that the powders made from cabbage, regardless of the method of their production, have high regradation properties not only in the aqueous phase, but also in solutions of sodium chloride and sucrose, which are traditionally used in the production of food products [4]. 
To assess the ability to crystallize the DFP polysaccharides, a diffractometer of the DRON$3 \mathrm{M}$ type of Burevestnik (Russia) was used in the $\mathrm{CuK} \alpha$ emission (nickel filter), $\mathrm{U}=30 \mathrm{kV}, \mathrm{I}=\mathrm{mA}$, $\Delta 2^{\theta}=0.04, \tau=3 \mathrm{~s}$.

The IR spectra of the disturbed total internal reflection were recorded for DFP grated powdered samples, the optical element was diamond, and the angle of the incident ray was $\theta=45^{\circ}$. The range is $4000 \ldots 400 \mathrm{~m}^{2}$, the number of scans was 128 , the resolution was $0.04 \mathrm{~m}$. The background was recorded with respect to the optical element without a sample.

The depth of penetration of infrared radiation into the sample $\left(\mathrm{d}_{\mathrm{e}}\right)$ as a function of the radiation wavelength $(\lambda)$ was calculated by the formula1:

$$
\mathrm{d}_{\mathrm{e}}=\frac{\lambda}{2 \pi \mathrm{n}_{\mathrm{O}} \sqrt{\left[\sin ^{2} \theta-\left(\frac{\mathrm{n}_{\mathrm{S}}}{\mathrm{n}_{\mathrm{O}}}\right)^{2}\right]}},
$$

where $n_{s}-$ the refractive index of light by the sample; $n_{o}$ - an optical element.

The aroma number (AN) of the DFP was determined by an original technique based on the titrimetric method. The essence of the method lies in the fact that during the interaction of essential oils with the chromium mixture, their oxidation takes place due to oxygen, it releases potassium dichromate $\mathrm{K}_{2} \mathrm{Cr}_{2} \mathrm{O}_{7}$ :

$$
\mathrm{Cr}_{2}\left(\mathrm{SO}_{4}\right)_{3}+\mathrm{K}_{2} \mathrm{SO}_{4}+4 \mathrm{H}_{2} \mathrm{O}+3 \mathrm{O}_{2} \rightarrow \mathrm{K}_{2} \mathrm{Cr}_{2} \mathrm{O}_{7}+4 \mathrm{H}_{2} \mathrm{SO}_{4}
$$

The sorption properties were determined by the tensometric method. For this, a sample of the material was transferred to a desiccator with a solution of sulfuric acid in an amount of $100 \mathrm{~cm}^{3}$ (acid concentrations: 50, 43, 38, 33, 27, 21, 17 and $11 \%$ ). The material sample was weighed until its mass became constant. This indicates the attainment of an equilibrium state, corresponding to the corresponding equilibrium moisture content of the sample.

\section{Results}

The ability to absorb moisture, according to the concept of work, is the main DFP qualitative characteristics. Wetted hygroscopic surface is characterized not only by the chemical composition, but also by the structural state of the substance of this surface. As a result of drying processes, the powder particles contain soluble and insoluble compounds on the surface.

Analysis of polysaccharides, which is in a significant amount in cabbage, and accordingly form a crystalline phase on the surface of the powder particles during drying and, first of all, determine its hygroscopicity, conducted X-ray structural studies (Fig. 1).

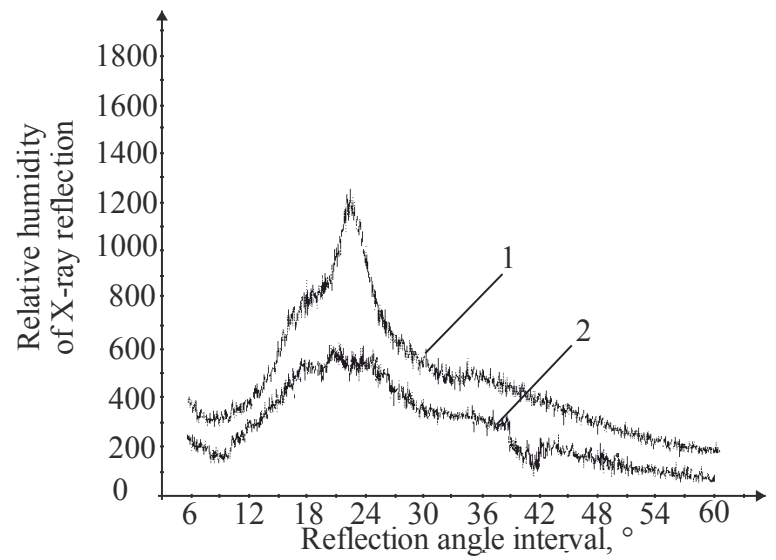

Fig. 1. DFP diffractograms made from MHS drying cabbage (1) and convection drying (2) 
The character of the diffractogram curves (Fig. 1) indicates that cabbage powders obtained by convection and MHS drying methods exhibit a partially ordered structure due to the presence of polysaccharide crystals. Their macromolecules are able to rotate the plane of polarization of light rays and form double helices [5-7].

Curve 1 in Fig. 1 has a high degree of crystallinity of polysaccharides, which indicates a smaller conversion of the components of the raw material in the case of superficial MHS drying conditions compared with convective conditions.

The effect of MHS drying temperature regimes on the formation of rehydration properties of the cabbage samples under study was determined by the method of recording IR spectra with Fourier transform - Fig. 2. To study the effect of drying regimes, fresh cabbage (as a control) was used as test samples, cabbage powders obtained by MHS drying at 50 and $70{ }^{\circ} \mathrm{C}$, and the powder was reduced.

The selected temperature of MHS drying is based on the fact that at temperatures below $50{ }^{\circ} \mathrm{C}$, the drying process grows and this requires considerable energy costs; above $70{ }^{\circ} \mathrm{C}$, the natural micro-nutrients of the raw materials are destroyed and the organoleptic and functional-technological properties deteriorate.

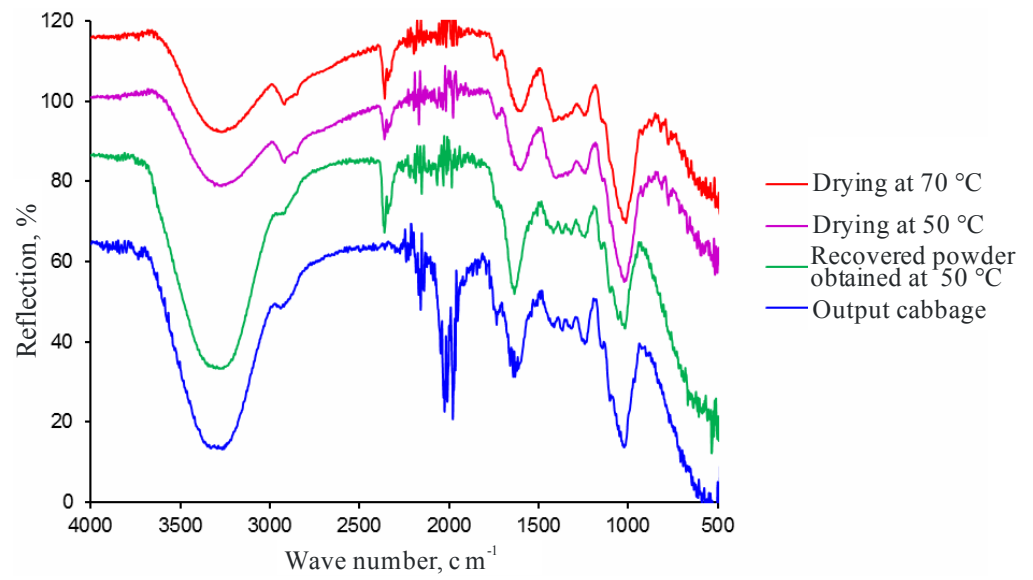

Fig. 2. Disturbed total internal reflection IR spectra of the DFP samples (the baseline spectra are biased to prevent their superposition)

From the results (Fig. 2), it is visible, that the maintenance of free moisture in initial cabbage is high. This is indicated by an intense maximum at $3300 \mathrm{~cm}^{-1}$, corresponding to stretching vibrations of $\mathrm{O}-\mathrm{H}(\mathrm{v}(\mathrm{OH}))$ bonds in water molecules connected by hydrogen bonds. The band at $1640 \mathrm{~cm}^{-1}$ corresponds to deformation vibrations $(\delta(\mathrm{HON}))$ of water molecules; intensive absorption in the $800 \ldots 400 \mathrm{~cm}^{-1}$ region is due to the librational (rotational) vibrations of water molecules in the liquid phase $\left(\mathrm{v}_{\mathrm{L}}\left(\mathrm{H}_{2} \mathrm{O}\right)\right)$, and the absorption band at $2030 \mathrm{~cm}^{-1}$ corresponds to the frequency $\left(\delta+v_{\mathrm{L}}\right)[8]$.

Other absorption bands in the fresh cabbage sample spectrum characterize the stretching vibrations of various organic compounds with $\mathrm{C}-\mathrm{H}$ bond groups $\left(2800 \ldots 3000 \mathrm{~cm}^{-1}\right), \mathrm{C}=\mathrm{O}\left(1740 \mathrm{~cm}^{-1}\right)$ and $\mathrm{C}-\mathrm{O}\left(1050 \mathrm{~cm}^{-1}\right)$.

MHS drying of cabbage at $50{ }^{\circ} \mathrm{C}$ (Fig. 2) leads to a significant decrease in the intensity of all bands characterizing the state of the water phase. In this case, the "combined" water band $\left(\delta+v_{L}\right)$ at $2030 \mathrm{~cm}^{-1}$ disappears completely. The decrease in the intensity of the water bands leads to the fact that the bands of organic fragments in the spectrum are much better, and the structure of the bands in the range $1200 \ldots 1500 \mathrm{~cm}^{-1}$ undergoes changes. This can indicate both possible chemical transformations with organic groups, and a change in their structural environment (hydration/dehydration).

The spectrum of cabbage dried at $70{ }^{\circ} \mathrm{C}$ (Fig. 2) is practically identical to the spectrum of a cabbage sample obtained at $50^{\circ} \mathrm{C}$ both from the intensity of the absorption bands of water and from the shape of bands of organic components. Thus, the use of temperatures of more than $50{ }^{\circ} \mathrm{C}$ in the case of MHS drying for this DFP is not advisable. 
The cabbage spectrum obtained after rehydration of the dried at $50{ }^{\circ} \mathrm{C}$ sample is very close to the spectrum of fresh cabbage: the bands of organic groups in the ranges $2800 \ldots 3000$ and $900 \ldots 1500 \mathrm{~cm}^{-1}$ in these spectra are completely identical. So, the "drying-rehydration" cycle does not lead to profound irreversible chemical transformations with these groups, which could be detected by IR spectroscopy. Almost identical (both in position and in intensity) there are absorption bands of the water phase at 3300, 1640 and $800-400 \mathrm{~cm}^{-1}$. However, the spectrum of rehydrated cabbage powder has some differences compared to the fresh cabbage spectrum: there is no "combined" water band $\left(\delta+v_{L}\right)$ at $2030 \mathrm{~cm}^{-1}$, the intensity of the carbonyl group band $v(\mathrm{C}=\mathrm{O})$ at $1740 \mathrm{~cm}^{-1}$ in it much less compared to both the spectrum of dried and fresh cabbage.

According to [9], the presence of a "combined" maximum at $2030 \mathrm{~cm}^{-1}$ is a sign of the presence of large clusters of an aqueous phase not connected with other substances. The absence of this band in the spectrum of rehydrated cabbage (in the presence of all other high-intensity bands) is a sign that upon rehydration the aqueous phase fills the developed pores with formation during MHS drying and binds to the organic substances of cabbage. The decrease in the band of carbonyl groups, has a significant intensity in the spectra of both dried and initial cabbage, may be due to the interaction of these groups (for example, groups of carboxylic anhydrides, lactones, etc.) with a solvent. So, the cycle "drying-rehydration" leads to an increase in the availability of organic matter of cabbage in relation to water, which may have a perspective, for example, for extracting organic substances from cabbage during its further processing.

The obtained results indicate that MHS drying promotes the maximum preservation of the native properties of the constituents of the feedstock and the formation of a capillary-porous structure in the powder particles, which allows increasing the amount of adsorption-bound moisture during their reduction. In the restored powder, the reflection value, characterizing the strong adsorption bonds of the powder components with water, is 1.8-2.0 times lower in comparison with the initial raw material.

The depth of changes in the product during drying leads to appropriate changes in the equilibrium of some chemical compounds, including those that cause the odor of the recovered raw materials and are determined by the amount of flavor. In Fig. 3, the quantitative content of the aromatic substances of the test samples is given.

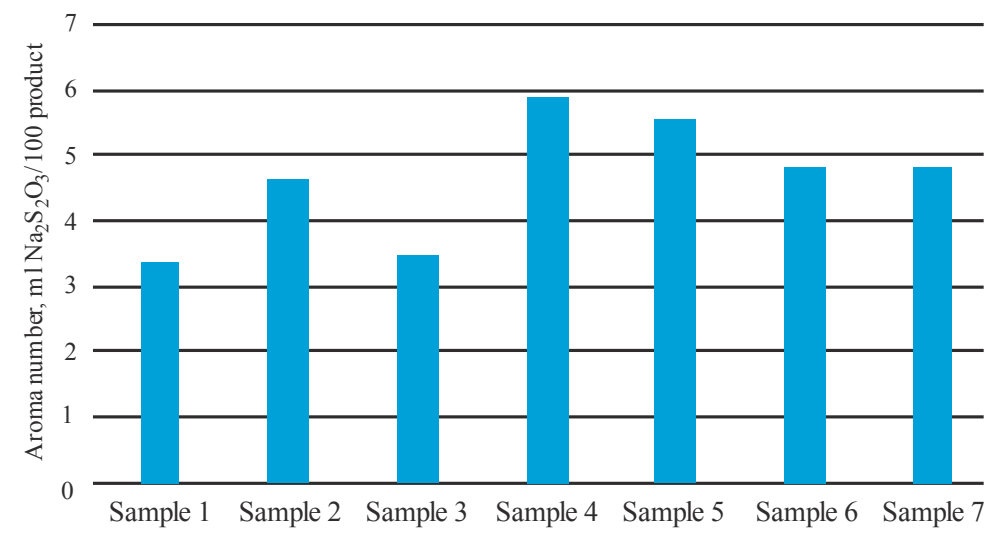

Fig. 3. The number of fragrance samples made from cabbage: 1 - fresh; 2 - convective drying powder; 3 - convective drying powder reduced in water; 4 - MHS drying powder at $50{ }^{\circ} \mathrm{C}$;

5 - MHS drying powder at $70{ }^{\circ} \mathrm{C} ; 6$ - MHS drying powder reduced in water at $50{ }^{\circ} \mathrm{C}$; 7 - MHS drying powder reduced in water at $70{ }^{\circ} \mathrm{C}$

Analysis of the histograms (Fig. 3) indicates that, after drying, the content of aroma-forming substances in $100 \mathrm{~g}$ of powder is greater in MHS drying than in convective. This is due to the reduction of the thermal action of the coolant on the raw materials during MHS drying, which slows the chemical transformations and the destruction of flavoring substances. After the reduction of powders obtained by the MHS drying method, regardless of the drying temperature, the amount of aroma is 1.4 times higher than the corresponding index of convective drying. The higher the 
value of the aroma number, the higher the score for the organoleptic evaluation of products, which includes the powder of cabbage.

General trends and obtained results of studies of the aroma number of DFP made from cabbage are correlated and confirmed by IR spectroscopy.

The ability of DFP to dehydrate during drying and rehydration in the process and during storage is due to the binding and content of water molecules by functional groups and a capillary-porous structure. Therefore, a measurement of the pore size by the strain gauge method has been carried out. In Fig. 4, experimental isotherms of sorption-desorption of cereals from cabbage are given.
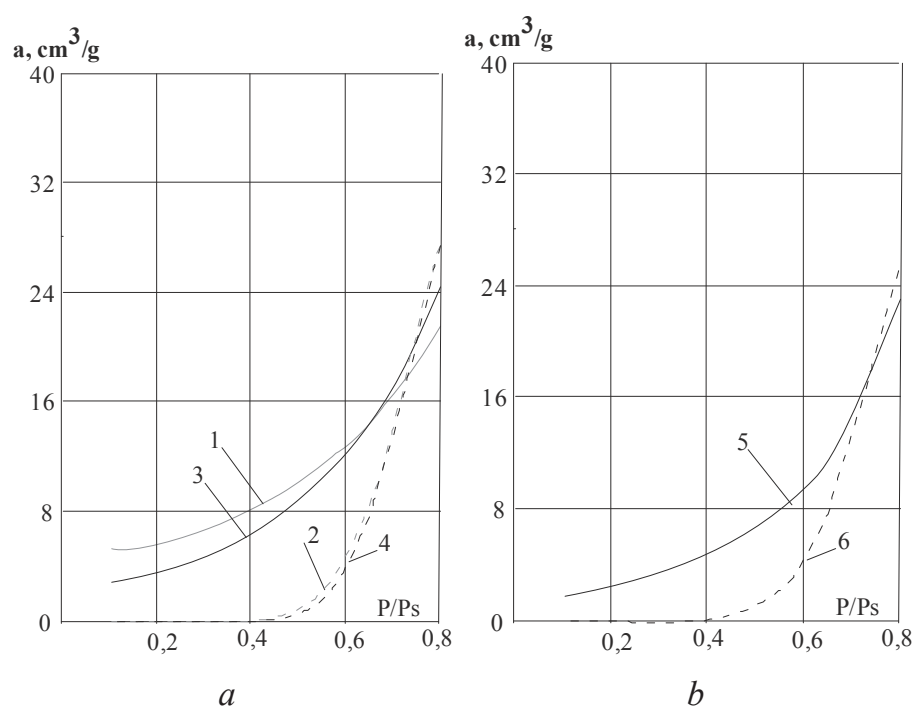

Fig. 4. Isotherms of sorption-desorption of powder made from:

$a$-MHS drying cabbage; $b$ - convective drying method; curves 1 and 2 - isotherms of sorption and desorption of cabbage powder obtained at $\mathrm{t}=50{ }^{\circ} \mathrm{C}$; curves 3 and 4 - isotherms of sorption and desorption of cabbage powder obtained at $\mathrm{t}=70{ }^{\circ} \mathrm{C}$; curves 5 and 6 - isotherms of sorption and desorption of cabbage powder of convective drying

The approximating function of the sorption-desorption isotherms (tensometry) can be described by the equation (2):

$$
\varphi=\frac{\mathrm{w}^{\mathrm{n}}}{\mathrm{A}_{1}+\mathrm{A}_{2} \mathrm{~W}^{\mathrm{n}}},
$$

where A, $\mathrm{n}$ - the coefficients determined from the experimental data associated with the parameters of the differential pore distribution function (DPDF) in radii; $\varphi$ - relative air humidity, $\%$; $\mathrm{W}$ - moisture content, $\mathrm{kg} / \mathrm{kg}$.

The distribution of pores along the radii of cereals from cabbage is given in Table $\mathbf{1}$.

\section{Table 1}

Distribution of pores along the radius of DFP made from cabbage

\begin{tabular}{ccccc}
\hline DFP & \multicolumn{2}{c}{$\mathbf{R}_{\mathbf{m}} \times \mathbf{1 0}^{-\mathbf{9}}, \mathbf{m}$} & \multicolumn{2}{c}{$\check{\mathbf{R}}^{\prime} \times \mathbf{1 0}^{-\mathbf{9}}, \mathbf{m}$} \\
\cline { 2 - 5 } & desorption & sorption & desorption & sorption \\
\hline from convective drying cabbage (control) & 1,10 & 2,55 & 20,90 & 25,80 \\
from MHS drying cabbage at $\mathrm{t}=50^{\circ} \mathrm{C}$ & 1,48 & 2,36 & 18,10 & 2,40 \\
from MHS drying cabbage at $\mathrm{t}=70^{\circ} \mathrm{C}$ & 1,44 & 2,20 & 11,50 & 2,00
\end{tabular}


As can be seen from Fig. 4 and Table 1, the differential distribution function of the porous (DPDF) of DFP, obtained by traditional convective and MHS drying, has a fundamentally different character [10]. It is found that with the first method of drying due to shrinkage during dehydration, the changes during sorption and desorption are insignificant. When MHS drying, such changes are clearly pronounced: during the sorption of fumes, DFP is well restored, the capillaries swell, so the DPDF expands. The average radius of the DFP capillaries obtained by MHS drying increases 4...6 times.

DPDF data indicate the formation of an artificial fine-mesh structure of the powder in the process of MHS drying - the most probable radius of the capillaries is greater than when convective drying.

It is proved that the existing structure of vegetable powders by MHS drying is characterized by fine pores at a temperature of MHS drying of $50{ }^{\circ} \mathrm{C}$ and a larger size of $1,2 \ldots 1,5$ times $-70{ }^{\circ} \mathrm{C}$.

The results of researches testify that application of method MHS drying at $50{ }^{\circ} \mathrm{C}$ more rational as allows to receive the developed capillary-porous structure and to generate the set functional and technological properties (especially rehydration) of a powder.

\section{Conclusions}

1. X-ray diffraction analysis has shown that under rational MHS drying regimes, a more porous structure of DFP is formed from cabbage, in contrast to the compacted samples with the crystalline structure of the polysaccharides of the convective process.

2. The water-retaining capacity of powders made from MHS drying cabbage is determined by means of infrared spectra in the scanning range of $500-4000 \mathrm{~cm}^{-1}$. Comparing the intensity of the IR spectra of the bands of $\mathrm{O}-\mathrm{H}$ bonds in the region of deformation vibrations of $3300 \mathrm{~cm}^{-1}$ and $1640 \mathrm{~cm}^{-1}$, it was determined that the amount of knitted moisture in MHS drying powders after reduction is only $\sim 2$ times less than the initial raw material.

3. The dependence of the method and the drying regimes of the powder, allowing the most complete preservation of aroma-forming substances, are established from the cabbage aroma by the number of DFP aromas.

4. It is proved that as a result of shrinkage during dehydration, which takes place in the convective drying of cereals from cabbage, the changes in sorption and desorption are insignificant. When MHS drying in the process of vapor sorption, DFP is well restored, the capillaries swell, so the DPDF expands, the average radius of the capillaries increases, which proves their improved technological properties.

The practical value of the data lies in the possibility of modeling the formulation composition and optimizing technological parameters for the production of food products using powdered cabbage.

The obtained results characterize the formation of porous structure and rehydration in powder from cabbage. In the case of applying MHS drying at a temperature of $50{ }^{\circ} \mathrm{C}$, these regularities require additional refinement.

The complex of researches of qualitative indicators of DFP made from cabbage will be used for mathematical modeling of the complex index of functional and technological properties depending on the MHS drying regimes and the dispersion of powder particles.

\section{References}

[1] Niemirich, O. V., Vasheka, O. M., Havrysh, A. V., Yevlash, V. V., Tarasenko, T. H. (2015). Teoretychne doslidzhennia sposobiv sushinnia ovochiv ta fruktiv. Naukovyi visnyk Lvivskoho natsionalnoho universytetu veterynarnoi medytsyny ta biotekhnolohii imeni S. Z. Gzhytskoho, 17 (4 (64)), 146-158.

[2] Niemirich, O. V., Vasheka, O. M., Yvanenko, O., Tarasenko, T. (2014). Doslidzhennia rehidratatsiynykh vlastyvostei poroshku kapusty. Canadian Journal of Science, Education and Culture, 2 (6), 263-268.

[3] Niemirich, A., Petrusha, O., Yasyuchenko, A., Drozd, D. (2015). Research of reducing and emulsifying abilities of vegetable and fruit powder. Eastern-European Journal of Enterprise Technologies, 3 (10 (75)). 26-30. doi: https://doi.org/10.15587/1729-4061.2015.43715 
[4] Yevlash, V. V., Niemirich, O. V., Malafaiev, M. T. (2012). Strukturno-mekhanichni kharakterystyky mlyntsevoho tista z poroshkom z kapusty. Khlebolekarskoe y kondyterskoe delo, 4 (43), 20-22.

[5] Belitz, H.-D. Grosch, W., Schieberle, P. (2009). Food Chemistry. Springer, 1070. doi: https:// doi.org/10.1007/978-3-540-69934-7

[6] Cui, S. (Ed.) (2005). Food Carbohydrates: Chemistry, Physical Properties and Applications. CRC Press, 432. doi: ttps://doi.org/10.1201/9780203485286

[7] Shujun, W. Jinglin, Yu., Wenyuan, G. (2005). Use of x-ray diffractometry (XRD) for identification of Fritillaria according to geographical origin. American Journal of Biochemistry and Biotechnology, 1 (4), 199-203. doi: https://doi.org/10.3844/ajbbsp.2005.199.203

[8] Lugovskoy, A. A., Poplavskii, Y. A., Serdyukov, V. I., \& Sinitsa, L. N. (2011). Experimental setup for spectrophotometric study of water clusters in nanoporous material. Atmospheric and Oceanic Optics, 24(5), 502-507. doi: https://doi.org/10.1134/s1024856011050125

[9] Ozaki, Y., McClure, W. F., Christy, A. A. (Eds.) (2006). Near-Infrared Spectroscopy in Food Science and Technology. Wiley-Interscience, 408. doi: https://doi.org/10.1002/0470047704

[10] Karge, H. G., Weitkamp, J. (Eds.) (2008). Adsorption and Diffusion, Springer Science \& Business Media, Berlin, 400. doi: https://doi.org/10.1007/978-3-540-73966-1

\title{
DEVELOPMENT OF THE NEW POINT SCALE OF ORGANOLEPTIC EVALUATION AT MANUFACTURING ORGANIC CAKES
}

\author{
Alina Tkachenko \\ Department of commodity of foodstuff \\ Higher Educational Establishment of Ukoopspilka «Poltava University of Economics and Trade» \\ 3 Koval str., Poltava, Ukraine, 36014 \\ alina_biaf@ukr.net
}

\begin{abstract}
The article presents the ground of developing the 50-point scale for evaluating cakes by organoleptic parameters. The aim of the article is to create the new point scale of organoleptic evaluation for using at producing organic cakes. It was established, that for today such important parameters as "flavor", "post-flavor", "porosity structure" are not always used at the organoleptic evaluation of cakes' quality. The article describes the recipes of four developed cakes, produced of the organic raw materials - "Grechanyk", based on buckwheat flour, "Zhytnytsa', based on rye flour, "Golden amaranth", based on amaranth flour and "Hempen delight", based on hempen flour. For evaluating organoleptic characteristics of cakes, there was presented 50-point scale that includes evaluation of the following parameters: form, surface condition, color of crust, condition and color of crumble, porosity structure, smell, taste, flavor, post-taste, malaxation of crumble. Based on the method of expert evaluations, there were determined significance coefficients for each parameter. Thus, coefficient 0,5 was set for the parameters "porosity structure" and 1,5 for "color" and "smell", the significance coefficient was equal 1 for a series of other parameters. The developed scale provided the following criteria of cakes evaluation: 45-50 points - "perfectly", 40-44 points - "well", 30-39 points - "satisfactorily", lower 30 points - "unsatisfactorily". Based on the developed scale, the developed cakes were evaluated by the gustatory commission. All developed cakes corresponded to the mark "perfectly" by organoleptic parameters. The highest index of the quality level was inherent to the cake "Grechanyk" " $-0,99$ at general sum of points for the gustatory evaluation 49,95 . The cake Zhytnytsa corresponded to 0,98 by the quality level, "Hempen delight" $-0,96$. The lowest quality level was detected in the cake "Golden amaranth" $(0,94)$, that is caused by the specific taste of amaranth flour.
\end{abstract}

Keywords: point scale, significance coefficient, organoleptic parameters, organic cakes, quality level.

DOI: 10.21303/2504-5695.2018.00666

(C) Alina Tkachenko

\section{Introduction}

Sensor or organoleptic methods, based on the analysis of feelings of human sense organs, are widely used for evaluating consumption advantages of food products [1] Earlier there were offered the methods of mathematical statistics, numerical modeling and forecasting that give a 